\title{
The proinflammatory role of lipoxygenases in rheumatoid arthritis
}

\author{
Jarosław Bryda', Sławomir Wątroba² \\ ${ }^{1}$ Department of Veterinary Hygiene, Voivodship Veterinary Inspectorate, Lublin, Poland \\ ${ }^{2}$ Department of Neonatology and Neonatal Intensive Care Unit, Independent Public Healthcare, Puławy, Poland \\ Bryda J, Wątroba S. The proinflammatory role of lipoxygenases in rheumatoid arthritis. J Pre-Clin Clin Res. 2018; 12(4): 129-134. \\ doi: $10.26444 /$ jpccr/99597
}

\begin{abstract}
Introduction. Rheumatoid arthritis (RA) is a chronic, systemic disease of connective tissue with autoimmune background. There is a lack of knowledge about the direct pathophysiological cause of RA formation. The involvement of lipoxygenase (LOX) in arachidonic acid (AA) metabolism can have a significant impact on the occurrence of RA. Lipid mediators play a significant role, inducing structural and metabolic changes in cells that initiate the activation of proinflammatory pathways and immune responses.

Objective. The purpose of this review is to analyze the involvement of LOX in the etiopathogenesis of RA, with particular emphasis on 5-LOX and 15-LOX, as well as the characteristics of LOX enzymatic activity and identification of the role of AA metabolites in the inflammatory reaction process.

State of knowledge. The effects of oxidative activity of LOX and dysfunctions of intracellular antioxidant systems lead to disturbance of redox homeostasis. The observed consequence of these phenomena are aberrations in the functioning of the immune system and accompanying inflammation. In RA studies, increased activity of 5-LOX and its reaction products was observed, such as leukotrienes B4 (LTB4) and 5-hydroxyeicosatetraenoic acid (5-HETE) in patients. A significant influence on the progression of RA is also associated with overexpression of 15-LOX, which leads to inhibition of chondrocyte proliferation and their apoptosis.

Conclusion. The activity of the oxidative enzyme LOX is involved in the formation of lipid mediators responsible for inducing inflammation. The effects of the action of LOX may be disorders of the immune system that contribute to the development of RA.
\end{abstract}

\section{Key words}

lipoxygenase, rheumatoid arthritis, inflammation, leukotrienes, metalloproteinases

\section{INTRODUCTION}

Lipoxygenases (LOX, EC 1.13.11.) are oxidoreductases class enzymes, a subclass of dioxygenases, commonly found in plant and animal organisms as well as some fungi, algae and cyanobacteria [1]. They catalyze the oxidation reactions of polyunsaturated fatty acids (PUFAs) containing cis, cis1,4-pentadienoic bonds, and their esters till conjugated unsaturated fatty acids and lipid hydroperoxides. The substrates of these reactions are arachidonic acid (AA), commonly found in the lipids of mammalian cell membranes, and linoleic (LA) and linolenic acids (ALA) found in plant organisms [2]. In plants, the activity of LOX leads to the formation of oxylipines involved in the regulation of many physiological processes, including germination, defence reactions to stress, or the synthesis of plant hormones [3]. In humans, the same as in mice, six LOX isoforms have been identified (15-LOX, 15-LOX-2, 12-LOX, 12R-LOX, eLOX3 , 5-LOX). In mammals, these enzymes are expressed in epithelial, immune and neoplastic cells, displaying a variety of biological functions. Their effects are also observed in inflammation, skin disorders and cancer [4].

Adress for correspondence: Jarosław Bryda, Department of Veterinary Hygiene Voivodship Veterinary Inspectorate, Lublin, Poland, ul. Droga Męczenników Majdanka 50, 20-325 Lublin, Poland

E-mail: brydajarek@gmail.com

Received: 22 September 2018; Accepted: 5 November 2018

\section{OBJECTIVE}

The aim of this brief review was to present the role of 5-LOX and 15-LOX and the products of their catalyzed reactions as pro-inflammatory mediators in the pathophysiology of RA. Important reports on the activity of lipoxygenases in RA in in vitro and in vivo models have been highlighted. LOX, their catalytic activity, activation mechanism and biologically active reaction products in mammalian organisms are also briefly characterized.

\section{MATERIALS AND METHOD}

Structure and mechanism of the LOX reaction. LOX are composed of single corrugated polypeptide chains with a molecular mass of 75-80 $\mathrm{kDa}$ in animals and 94-104 $\mathrm{kDa}$ in plants. In their structure they have two domains, a shorter $\mathrm{N}$-terminal $\beta$-cylindrical and a longer $\mathrm{C}$-terminal helictic containing the active site of the enzyme. The longer domain is surrounded by a single atom of non-heme iron $[1,5]$.

The best known and characterized is LOX-1 derived from soybeans. It serves as a biochemical model for research on the mechanism of reactions carried out by LOX. This is due to the possibility of the relatively easy isolation of this enzyme and its considerable stability [6]. The structure of mammalian LOX enzymes seems to be similar. However, it should be noted to each isoform has unique properties, such as substrate specificity $[4,7]$. 
The structure of model soybean LOX-1 shows the presence of 839 amino acid residues, which include two domains. Domain I contains 146 residues and the N-terminal amino acid, domain II consists of 693 residues and a C-terminal amino acid. LOX is a metalloprotein containing at the centre of the C-terminal domain an iron atom that is coordinated with five endogenous ligands (His 499, His 504, His 690, Ile 839, Asn 694), and a coordination site for water binding, particularly important for catalytic activity. In the inactive form of the enzyme, iron is present in the second oxidation state, which under the influence of oxygen undergoes activation transforms to $\mathrm{Fe}(+3)[5,8]$.

Activation of the enzyme requires the presence of hydroperoxides of fatty acids or hydrogen peroxide as catalysts, at which the participation the oxidation of the iron atom occurs. The presence of hydroperoxides is the result of the autoxidation reaction. Indirectly, they can also be produced by the action of small amounts of active LOX. As a result of activating the enzyme, the resulting reaction products are used to activate further enzyme particles, and in this way the proper hydroperoxide formation takes place $[1$, $2,9]$. The first stage of the reaction is removal of a hydrogen atom as proton from the substrate, pro-S from the methylene group located between the double bonds, resulting in the formation of a fatty acid radical, and there is iron reduction at the active site of the enzyme (Fig.1.1). The second stage of the catalytic reaction takes place in the anaerobic or aerobic cycle. In the absence of oxygen, the radical is dissociated from the enzyme and the radical becomes a substrate in free radical reactions (FRR) (Fig.1.5). In aerobic conditions, the radical-enzyme complex does not break down, the addition of oxygen creates a peroxide radical of the fatty acid (Fig.1.2) and it is subsequently converted into the peroxide anion (Fig.1.3). Simultaneously, iron oxidation takes place in the active centre of the enzyme. The peroxide anion reacts with the hydrogen ion to form a fatty acid hydroxide which dissociates from the enzyme (Fig. 1.4). After completion of the catalytic cycle, the enzyme is ready to carry out further reactions [2, 9-11].

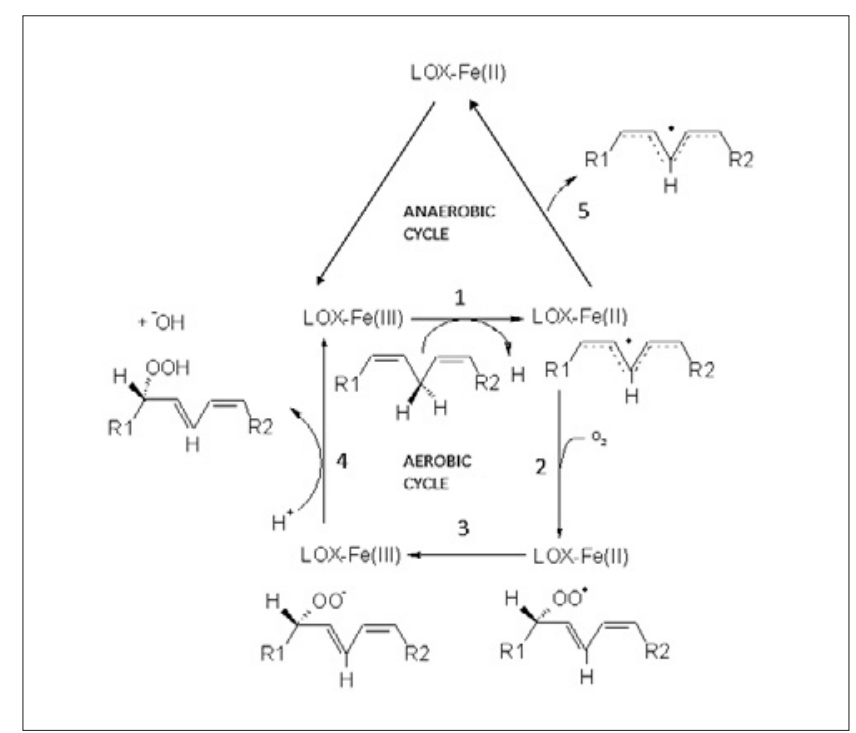

Figure 1. Catalytic cycle of the LOX reaction [11 modified].

Biological products of LOX in mammals. LOX play an important role in mammalian organisms, which include regulation of redox cellular homeostasis, gene expression and participation in cell proliferation and differentiation. Their activity also contributes to the formation of inflammation, involvement in the pathophysiology of metabolic, neurodegenerative, immunological, hyperproliferative and infectious diseases. They initiate the formation of free radicals contributing to harmful lipid oxidation reactions. Recently, the role of the main products of metabolism catalyzed by LOX in monitoring the progression of chronic kidney disease (CKD) is also underlined. [4, 12-15].

LOX are involved in inflammatory reactions of the body, contributing to the formation of mediators of the inflammatory process. A significant part of these compounds originates from PUFAs [16]. The substrate for reactions catalysed by LOX in mammalian cells is AA that is released from membrane phospholipids by phospholipase A2 (PLA2s). As a result of the action of LOX, non-cyclic compounds, such as leukotrienes (LT), 5-, 12- and 15-hydroperoxyeicosatetraenoic acids (HpETE) and hydroxyeicrosatetrae (HETE), are formed [17, 18]. LT are formed in various types of leukocytes and other cells with immune competence. Their biosynthesis takes place in the 5-LOX enzymatic pathway from free AA. The first stage of the reaction is oxygenation of AA to 5S-HpETE, followed by conversion of 5S-HpETE to LTA4. LT can be divided into two classes: peptido-LTs - leukotrienes C4, D4, E4 (LTC4, LTD4, LTE4) and peptide-free LTs - leukotriene B4 (LTB4) [12]. The resulting eicosanoids are characterized by high biological activity. They stimulate strong allergic and inflammatory reactions, form clots, contribute to atherosclerotic changes, and are responsible for the growth of cancerous tissue in such organs as the prostate and colon $[17,18]$.

Some reaction products catalyzed by LOX, such as lipoxins A4 (LXA4) and its epimer 15-epi-LXA4, may also have antiinflammatory activity. This action is based on the stimulation of the ALX receptor (ALX-r), which occurs particularly in leukocytes and leads to suppression of the inflammatory response. The action of lipoxins in in vivo studies show that they are unstable and they are enzymatically inactivated $[16,19]$

In addition to participating in the production of biologically active lipid mediators, LOX may also be active by two other mechanisms: I-modifications of protein-lipid complexes, leading to impaired cell membrane function and II- by modifying cellular redox homeostasis affecting gene expression $[12,17]$.

Rheumatoid arthritis characteristics and diagnostic criteria. Rheumatoid arthritis (RA) is a chronic, immunologically dependent connective tissue disease, characterized by a progressive, non-specifically symmetrical, inflammatory reaction that progresses in the synovium of the affected joint. Inflammation of the synovium, along with the progression of the disease, is generalized and gradually involves the structure of the entire joint along with tendinous sheath and synovial bursa $[20,21]$. Due to the frequent occurrence of extra-articular changes and systemic complications, the disease often leads to disability [22].

RA affects about $0.5 \%-2 \%$ of the world's population [23], and in Poland, RA affects about $0.9 \%$ of the population [24]. The highest number of cases is recorded in the fourth and fifth decades of life, although the first symptoms of the disease may occur between the 2 nd and the 3 rd decade of life. RA is about four times more common in women [25]. 
Joint changes in RA are symmetrical and usually involve the small hand joints. Typically, they involve the metacarpophalangeal joints, proximal interphalangeal joints and wrist joints, often leading to carpal tunnel syndrome. Subsequently, inflammatory changes include the knee, ankle, shoulder and toe joints, as well as the joints of the cervical spine, which may cause subluxation and secondary neurological symptoms $[26,27]$. The most serious organ complications in the course of RA are vasculitis, pulmonary fibrosis and reactive amyloidosis [26, 28, 29].

The diagnostic criteria of RA developed in 2010 by the American College of Rheumatology and European League Against Rheumatism are summarized in Table 1 [30].

Etiopathogenesis of rheumatoid arthritis. Etiopathogenesis of RA is not fully known [31]. Due to the autoimmune basis of RA, its important role in pathogenesis is attributed to the abnormal effects of the immune system, expressed by the presence of antibodies against diverse structural elements of the body's own cells and tissues. For many years, the so-called rheumatoid factor (RF), which is the most wellknown autoantibody in RA, was considered to be specific in its pathogenesis [32]. As a result of many studies conducted, it has been proven that RF occurs in about $75 \%$ of patients suffering from RA; however, it can also occur in the course of other autoimmune diseases, such as systemic lupus erythematosus and Sjogren's syndrome [33]

A significant role in the initiation of the disease process is fulfilled by genetic predisposition, mainly genetically conditioned differences in the range of class II MHC antigens, especially HLA-DR4, reactive oxygen species, bacterial and viral infections, environmental factors and diet [34-37].

Due to the inflammatory basis of RA in its pathogenesis, it is impossible to omit the role of proteases belonging to matrix metalloproteinases (MMPs), the two most important roles in the destruction of joint cartilage - MMP-1 and MMP-13 and proinflammatory cytokines, such as interleukin $1 \beta$ (IL-1 $\beta$ ) and tumour necrosis factor $\alpha$ (TNF- $\alpha$ ) [38-40].

In the pathophysiology of RA, an important role is also attributed to the transformation of AA by cyclooxygenase (COX) and LOX. While the role of COX in RA has been known for a long time, the role of LOX is currently being widely studied [41-43].

Role of 5-LOX in rheumatoid arthritis. In many studies on the pathophysiology of RA, the role of 5-LOX in the reaction products catalyzed by it are underlined, namely LTB4 and 5-HETE [43-45]. The biological effect of LTB4 in the pathophysiology of inflammation manifests itself in the intensification of leukocyte and macrophage chemotaxis, increased leukocyte diapedesis into the extravascular space, stimulation of lymphocyte and macrophage proliferation, activation of PLA2s and increasing the production of free oxygen radicals. LTB4 is also a negative regulator of bone turnover by inhibiting osteoblast activity and stimulating osteoclast activity, and thus intensifying bone tissue degradation and inhibiting its formation $[46,47]$.

In the work of Davidson ret al. in 1983 [48], inflammatory synovial fluid in RA patients was found to contain, apart from numerous growth factors and cytokines, high levels of leukotrienes, mainly LTB4. It was also shown that LTB4 and 5-HETE are present in high serum concentrations of patients with active RA compared to the group of patients with an
Table 1. Diagnostic criteria of RA (American College of Rheumatology and European League Against Rheumatism, 2010) [30]

\section{Target population (who should be tested?) - patients who:}

1) have at least one joint with definite clinical synovitis (swelling)*

2) with the synovitis not better explained by another disease $\dagger$

Classification criteria for RA (score-based algorithm: add score of categories A - D; a score of $\geq 6$ out of 10 is needed for classification of a patient as having definite $\mathrm{RA}) \neq$

\begin{tabular}{|c|c|}
\hline \multicolumn{2}{|l|}{ A. Joint involvement § Score } \\
\hline 1 large joint $\|$ & 0 \\
\hline $1-10$ large joints & 1 \\
\hline $1-3$ small joints (with or without involvement of large joints) & 2 \\
\hline $4-10$ small joints (with or without involvement of large joints) & 3 \\
\hline$>10$ joints (at least one small joint) ${ }^{* *}$ & 5 \\
\hline \multicolumn{2}{|c|}{ B. Serology (at least one test result is needed for classification) t+ Score } \\
\hline Negative RF and negative ACPA & 0 \\
\hline Low positive RF or low positive ACPA & 2 \\
\hline High positive RF or high positive ACPA & 3 \\
\hline \multicolumn{2}{|l|}{$\begin{array}{l}\text { C. Acute phase reactants (at least one test result is needed for } \\
\text { classification) f\# Score }\end{array}$} \\
\hline Normal CRP and normal ESR & 0 \\
\hline Abnormal CRP or normal ESR & 1 \\
\hline \multicolumn{2}{|l|}{ D. Duration of symptoms §§ Score } \\
\hline$<6$ weeks & 0 \\
\hline$\geq 6$ weeks & 1 \\
\hline
\end{tabular}

ACPA - anti-citrullinated protein antibody; CRP - C-reactive protein; ESR - erythrocyte sedimentation rate; RA - rheumatoid arthritis.

* Criteria are aimed at classification of newly presenting patients. In addition, patients with erosive disease typical of RA with a history compatible with prior fulfillment of the 2010 criteria should be classified as having RA. Patients with long-standing disease, including those whose should be classified as having RA. Patientswith long-standing disease, including those whose disease is inactive (with or without treatment), who, based on retrospectively available data,
have previously fulfilled the 2010 criteria should be classified as having RA.

† - Differential diagnoses differ in patients with different presentations, but may include conditions such as systemic lupus erythematosus, psoriatic arthritis, and gout. If it is unclear about which relevant differential diagnoses to consider, an expert rheumatologist should be consulted.

$\ddagger-$ Although patients with a score of less than 6 out of 10 are not classifiable as having RA, their status can be reassessed, and the criteria might be fulfilled cumulatively over time.

$\S$ - Joint involvement refers to any swollen or tender joint on examination, which may be confirmed by imaging evidence of synovitis. Distal interphalangeal joints, first carpometacarpal joints, and first metatarsophal joint distribution are classified according to the location and number of involved joints, with placement into the highest category possible based on the pattern of joint involvement. placement into the highest category possible based on the pattern of
$\|$ - "Large joints" refers to shoulders, elbows, hips, knees, and ankles.

9ी - "Small joints" refers to the metacarpophalangeal joints, proximal interphalangeal joints, $2^{\text {nd }}-5^{\text {th }}$ metatarsophalangeal joints, thumb interphalangeal joints, and wrists.

** At least one of the involved joints must be a small joint; the other joints can include any combination of large and additional small joints, as well as other joints not specifically listed elsewhere (e.g., temporomandibular, acromioclavicular, sternoclavicular).

††- Negative refers to international unit values that are less than or equal to the upper limit of normal for the laboratory and assay; low positive refers to international unit values that are higher than the upper limit of normal but three or less times the upper limit of normal for are high or the laboratory and assay; high positive refers to international unit values that are more than three times the upper limit of normal for the laboratory and assay. When rheumatoid factor
information is only available as positive or negative, a positive result should be scored as low positive for rheumatoid factor.

\#キ-Normal/abnormal is determined by local laboratory standards.

$\S \S$ - Duration of symptoms refers to patient self-report of the duration of signs or symptoms of synovitis (e.g., pain, swelling, tenderness) of joints that are clinically involved at the time of assessment, regardless of treatment status.

inactive form of RA and those with no RA [49]. Interesting conclusions were also made by Chen et al. [50], conducted in mice without 5-LOX or LTB4, in which they were shown to be protected from RA development, which proves the important role of LTB4 in the development of this disease.

The role of 5-LOX in RA has been demonstrated in studies conducted by Gheorge et al. [49] on a group of six RA patients and five patients with osteoarthritis (OA). In this study, although it was performed on a low number group, 5-LOX was highly expressed in the synovial tissues 
of RA patients compared to patients with OA. Using dual immunofluorescence, the highest expression of the enzyme was found in CD163 + macrophages, CD68 + macrophages, $\mathrm{CD} 66 \mathrm{~b}+$ neutrophils and in tryptase-positive mast cells. However, no 5-LOX expression was found in synovial fibroblasts, T lymphocytes and B lymphocytes. In patients with OA 5-LOX showed little expression, which is in agreement with the Ahmadzadeh et al. [51] study, which found low LTB4 in liquid synovial fluid and a low degree of infiltration of the synovial membrane with inflammatory cells in patients with OA. In a study conducted by Goetzl et al. [52], LTB4 showed a chemotactic effect on neutrophils and eosinophils at a concentration of $3 \mathrm{ng} / \mathrm{ml}$ and 5-HETE at a concentration of $1000 \mathrm{ng} / \mathrm{ml}$, which proves their significant role in the induction of local inflammatory response, even at small concentrations in the synovial fluid.

LOX-15 in rheumatoid arthritis. Currently, there are a limited number of publications that promote the role of 15-LOX in chronic inflammation, but its role in the pathophysiology of inflammation and modulation of immunity has long been recognized. In humans, 15-LOX occurs in two isoforms - as 15-LOX and 15-LOX-2, which differ in tissue localization. 15 -LOX is predominantly found in macrophages, dendritic cells, eosinophils and the skin, whereas 15-LOX-2 in the skin, cornea, alveolar macrophages and the prostate gland $[49,53]$.

Referring to the biological functions of $15-\mathrm{LOX}-2$, in the conducted studies, its role in the pathophysiology of atherosclerosis in humans and animals is raised. Significant 15-LOX-2 expression was demonstrated in macrophages of atherosclerotic plaques in both humans and experimental mice $[54,55]$. In mice with blocked 15 -LOX-2 expression, socalled defective atherosclerosis was observed, which proves that in the mouse atherosclerotic model, high activity of 15LOX-2 is necessary for the development of the disease [55].

It was also proven in numerous studies that the 15-LOX-2 performs the atyproliferative function, stating a reduction the activity of 15-LOX-2 in epithelial-derived tumors [5658]. In addition, 15-LOX-2 is involved in the production of docosahexaenoic acid (DHA) anti-inflammatory neuroprotectin D1, for which, however, at the present state of knowledge, no effects in the pathophysiology of rheumatic diseases have been proved $[59,60]$.

15 -LOX is a lipid peroxide enzyme and has a proven pronounced pro-inflammatory effect. It converts AA to 15S-HpETE, which is highly unstable in the human body and is further converted to 15-HETE [49]. In addition, the participation of 15-LOX in the metabolism of AA has been found in small pro-inflammatory molecules, which work by increasing capillary permeability through a damaging effect on endothelial cells, as demonstrated in in vitro studies [61].

In studies comparing the expression of 15-LOX in the synovium of patients suffering from RA and OA, it was shown that it was significantly higher in RA patients. The cited study analyzed the synovium fragments obtained by biopsy from six RA patients and from five OA patients. The rabbit polyclonal anti-human 15-LOX isoform antibodies were used in the immunohistochemical diagnosis [49]. Positive staining for 15-LOX was detected in both connective tissue and blood vessel cells, as well as in mononuclear and neutrophil cells, accounting for nearly $70 \%$ of the total pool of synovial fluid cells in RA patients. The synovium tissue of patients suffering from OA showed a small expression of the 15-LOX isoform.
Interestingly, in the above study it was shown that after the corticosteroid local application there is no reduction of 15LOX expression, with simultaneous pronounced reduction of 5-LOX expression. In a study conducted by Liagre et al. [62], expression of 15-LOX in vascular endothelial cells was demonstrated; moreover, a correlation between 15-LOX expression and nuclear factor kappa-light-chain-enhancer of activated B cells (NF- $\kappa \mathrm{B}$ ) activity was demonstrated, which is important in enhancing chemotaxis of inflammatory immune cells into diseased tissues. Interestingly, despite the significant expression of 15 -LOX in the synovium, patients suffering from RA did not correlate with the concentration of 15 -HETE in synovial fluid. In addition to enhancing immune cell chemotaxis to the focus of inflammation through NF$\kappa \mathrm{B}$ induction, the proinflammatory action of 15-LOX in RA relies on increasing vascular permeability, increasing TNF- $\alpha$ expression in vascular smooth muscle, as well as inhibiting proliferation and induction of chondrocyte apoptosis [63]. Despite the proven proinflammatory effect, it should be emphasized that the reaction products catalyzed by 15 -LOX may paradoxically exhibit anti-inflammatory properties in RA as, for example, in the case of lipoxins. There is no doubt that 15-LOX plays a significant role in the pathophysiology of RA which, however, due to its dual action (both proinflammatory and potentially anti-inflammatory), requires further research $[49,64]$.

\section{CONCLUSIONS}

RA is a chronic autoimmune disease characterized by damage to the synovium, tendon sheaths and synovial tissues. In the course of the disease, which affects about $05 \%-2.0 \%$ of the population, there are often organ complications and numerous extra-articular changes that lead to disability. In the pathogenesis of RA, an important role is attributed to dysfunctions of the immune system, consisting in the induction of antibodies directed against the tissues of their own body. In the chronic inflammatory process, they also play the role of transformation of arachidonic acid through COX and LOX.

In the presented study, 5-LOX and 15-LOX have been given special attention in the pathophysiology of RA. Among the reaction products catalyzed by 5-LOX, LTB4 and 5-HETE are the largest contributors to the pathogenesis of RA. LTB4 activity is manifested by the activation of phospholipase A2, increasing the production of oxygen free radicals, intensification of leukocyte and macrophage chemotaxis, as well as the increase of leukocyte diapedesis into the extravascular space. LTB 4 is also a negative regulator of bone turnover, intensifies bone tissue degradation and significantly inhibits its formation.

15-LOX is a lipid peroxide enzyme and has proven proinflammatory action. In vitro studies have demonstrated the involvement of 15 -LOX in the metabolism of AA to small molecules, the effect of which is to increase capillary permeability. The pro-inflammatory activity of 15-LOX in RA also involves increasing the expression of TNF- $\alpha$ in vascular smooth muscle, as well as inhibiting proliferation and induction of chondrocyte apoptosis. A correlation between the expression of $15-\mathrm{LOX}$ and NF- $\mathrm{BB}$ activity was also demonstrated, which is important in enhancing the chemotaxis of inflammatory cells to the tissues involved in the disease process. Interestingly, despite the proven pro- 
inflammatory effect, the products of reactions catalyzed by 15 -LOX may also have anti-inflammatory properties, as is the case with lipoxins.

There is no doubt that LOX plays an important role in the pathophysiology of RA, but their participation in the development of the disease should be the subject of further research, among others, due to their potentially antiinflammatory effects.

\section{REFERENCES}

1.Brash AR. Lipoxygenases: occurrence, functions, catalysis, and acquisition of substrate. J Biol Chem. 1999; 274(34): 23679-23682.

2.Ivanov I, Heydeck D, Hofheinz K, Roffeis J, O’Donnell VB, Kühn H, et al. Molecular enzymology of lipoxygenases. Archives of biochemistry and biophysics. 2010; 503: 161-174.

3. Porta H, Rocha-Sosa M. Plant lipoxygenases. Physiological and molecular features. Plant Physiol. 2002; 130(1): 15-21.

4. Mashima R, Okuyama T. The role of lipoxygenases in pathophysiology; new insights and future perspectives. Redox Biol. 2015; 6: 297-310.

5. Baraniak BM, Szymanowska U. Lipooksygenaza w żywności pochodzenia roślinnego [Lipoxygenase in food of plant origin]. ŻNTJ. 2006; 47(2): 29-45.

6. Hayward S, Cilliers T, Swart. Lipoxygenases: From Isolation to Application. Compr Rev Food Sci Food Saf. 2016; 16(1): 199-211.

7.Wecksler AT, Garcia NK, Holman TR. Substrate specificity effects of lipoxygenase products and inhibitors on soybean lipoxygenase-1. Bioorganic \& medicinal chemistry. 2009; 17(18): 6534-6539.

8. Dainese E, Sabatucci A, van Zadelhoff G, Angelucci CB, Vachette P, Veldink GA, et al. Structural stability of soybean lipoxygenase-1 in solution as probed by small angle X-ray scattering. J Mol Biol. 2005; 349(1): 143-152.

9.Schilstra MJ, Veldink GA, Vliegenthart JF. The dioxygenation rate in lipoxygenase catalysis is determined by the amount of iron (III) lipoxygenase in solution. Biochemistry. 1994; 33(13): 3974-3979.

10.Zheng Y, Brash AR. On the role of molecular oxygen in lipoxygenase activation: comparison and contrast of epidermal lipoxygenase- 3 with soybean lipoxygenase-1. J Biol Chem. 2010; 285(51): 39876-39887.

11. Seta A, Skórzyńska-Polit E, Szczuka E, Giełwanowska I. Lipooksygenaza w komórkach roślinnych - budowa i funkcja [Lipooxygenase in plant cells - structure and function]. Post Biol Kom. 2009; 36(25): 69-83.

12. Kuhn H, Banthiya S, van Leyen K. Mammalian lipoxygenases and their biological relevance. Biochimica et biophysica acta. 2015; 1851(4): 308-330.

13. Yang L, Ma C, Zhang L, Zhang M, Li F, Zhang C, et al. 15-Lipoxygenase2/15(S)-hydroxyeicosatetraenoic acid regulates cell proliferation and metastasis via the STAT3 pathway in lung adenocarcinoma. Prostaglandins Other Lipid Mediat. 2018; 138: 31-40.

14. Lauretti E, Praticò D. Novel Key Players in the Development of Tau Neuropathology: Focus on the 5-Lipoxygenase. J Alzheimers Dis. 2018; 64(s1): S481-S489.

15. Afshinnia F, Zeng L, Byun J, Wernisch S, Deo R, Chen J, et al. Elevated lipoxygenase and cytochrome $\mathrm{P} 450$ products predict progression of chronic kidney disease. Nephrol Dial Transplant. 2018; doi: 10.1093/ ndt/gfy232.

16. Nowak JZ. Przeciwzapalne „prowygaszeniowe” pochodne wielonienasyconych kwasów tłuszczowych omega 3 i omega $6^{*}$ [Antiinflammatory pro-resolvingderivatives of omega-3 and omega- 6 polyunsaturatedfatty acids]. Postepy Hig Med Dosw. 2010; 64: 115-132.

17. Schneider I, Bucar F. Lipoxygenase Inhibitors from Natural Plant Sources. Part 2: Medicinal Plants with Inhibitory Activity on Arachidonate 12-lipoxygenase, 15-lipoxygenase and Leukotriene Receptor Antagonists. Phytother Res. 2005; 19(4): 263-272.

18. Jelińska M. Kwasy tłuszczowe - czynniki modyfikujące procesy nowotworowe [Fatty acids - factors modifying cancer processes]. Biul Wydz Farm. AMW, 1, 2005.

19. Wu R, Zhou W, Chen S, Shi Y, Su L, Zhu M, et al. Lipoxin A4 suppresses the development of endometriosis in an ALX receptor-dependent manner via the p38 MAPK pathway. Br J Pharmacol. 2014; 171(21): 4927-4940.

20. Calabresi E, Petrelli F, Bonifacio AF, Puxeddu I, Alunno A. One year in review 2018: pathogenesis of rheumatoid arthritis. Clin Exp Rheumatol. 2018; 36: 175-184.
21. Ramachandran HD. Rheumatoid arthritis: a review. 2014; 3(9): 1073 1106.

22. Ma VY, Chan L, Carruthers KJ. Incidence, prevalence, costs, and impact on disability of common conditions requiring rehabilitation in the United States: stroke, spinal cord injury, traumatic brain injury, multiple sclerosis, osteoarthritis, rheumatoid arthritis, limb loss, and back pain Arch Phys Med Rehabil. 2014; 95(5): 986-995.

23. Korczowska I. Rheumatoid arthritis susceptibility genes: An overview. World J Orthop. 2014; 5(4): 544-549.

24. Batko B, Stajszczyk M, Świerkot J, Urbański K, Raciborski F, Jędrzejewski $\mathrm{M}$, et al. Prevalence and clinical characteristics of rheumatoid arthritis in Poland: a nationwide study. 2017.

25. Tatara T, Snakowska P. Rola diety w reumatoidalnym zapaleniu stawówprzegląd systematyczny badań [The role of diet in rheumatoid arthritis - systematic review of research]. Med Rodz. 2015; 2(18): 70-78.

26. Arnett FC, Edworthy SM, Bloch DA, McShane DJ, Fries JF, Cooper NS, et al. The American Rheumatism Association 1987 revised criteria for the classification of rheumatoid arthritis. Arthritis Rheum. 1988; 31(3): 315-324.

27. Saraux A, Berthelot JM, Chalès G, Le Henaff C, Thorel JB, Hoang S, et al. Ability of the American College of Rheumatology 1987 criteria to predict rheumatoid arthritis in patients with early arthritis and classification of these patients two years later. Arthritis Rheum. 2001; 44(11): 2485-2491.

28. Gauhar U, Gaffo A, Alarcon G. Pulmonary Manifestations of Rheumatoid Arthritis. Semin Respir Crit Care Med. 2007; 28(4): 430-440.

29. Young A, Koduri G. Extra-articular manifestations and complications of rheumatoid arthritis. Best Pract Res Clin Rheumatol. 2007; 21(5): 907-927.

30. Aletaha D, Neogi T, Silman AJ, Funovits J, Felson DT, Bingham CO, et al. 2010 rheumatoid arthritis classification criteria: an American College of Rheumatology/ European League Against Rheumatism collaborative initiative. Ann Rheum Dis. 2010; 69(9): 1580-1588.

31. Picerno V, Ferro F, Adinolfi A, Valentini E, Tani C, Alunno A. One year in review: the pathogenesis of rheumatoid arthritis. Clin Exp Rheumatol. 2015; 33: 551-558.

32. Mannik M, Nardella FA. IgG rheumatoid factors and self-association of these antibodies. Clin Rheum Dis. 1985; 11(3): 551-572.

33. Van Boekel MA, Vossenaar ER, van den Hoogen FH, van Venrooij WJ. Autoantibody systems in rheumatoid arthritis: specificity, sensitivity and diagnostic value. Arthritis Res. 2002; 4(2): 87-93.

34. Alamanos Y, Drosos AA. Epidemiology of adult rheumatoid arthritis. Autoimmun Rev. 2005; 4(3): 130-136.

35. Matyska-Piekarska E, Łuszczewski A, Łącki J, Wawer I. Rola stresu oksydacyjnego w etiopatogenezie reumatoidalnego zapalenias tawów [The role of oxidative stress in the etiopathogenesis of rheumatoid arthritis] Postepy Hig Med Dosw. 2006; 60: 617-623.

36. Orozco G, Barton A. Update on the genetic risk factors for rheumatoid arthritis. Expert Rev Clin Immunol. 2010; 6(1): 61-75.

37. Kochi Y, Suzuki A, Yamamoto K. Genetic basis of rheumatoid arthritis: a current review. Biochem Biophys Res Commun. 2014; 452(2): 254-262.

38. Burrage PS, Mix KS, Brinckerhoff CE. Matrix metalloproteinases: role in arthritis. Front Biosci. 2006; 11: 529-543.

39. Welgus HG, Jeffrey JJ, Eisen AZ. The collagen substrate specificity of human skin fibroblast collagenase. J Biol Chem. 1981; 256(18): 95119515.

40. Wojdasiewicz P, Poniatowski Ł.A, Szukiewicz D. The Role of Inflammatory and Anti-Inflammatory Cytokines in the Pathogenesis of Osteoarthritis. Mediators of Inflammation. Mediators Inflamm. 2014; 2014:561459.

41. Liagre B, Vergne-Salle P, Corbiere C, Charissoux JL, Beneytout JL. Diosgenin, a plant steroid, induces apoptosis in human rheumatoid arthritis synoviocytes with cyclooxygenase-2 overexpression. Arthritis Res Ther. 2004; 6(4): 373-383.

42. Lee YH, Choi SJ, Kim A, Kim CH, Ji JD, Song GG. Expression of cyclooxygenase-1 and -2 in rheumatoid arthritis synovium. J Korean Med Sci. 2000; 15(1): 88-92.

43. Kapoor M, Fumiaki K, Crofford LJ. Arachidonic acid-derived eicosanoids in rheumatoid arthritis: implications and future targets. Future Rheumatol. 2006; 1(3): 323-330.

44. Lin HC, Lin TH, Wu MY, Chiu YC, Tang CH, Hour MJ, et al. 5-Lipoxygenase inhibitors attenuate TNF-alpha-induced inflammation in human synovial fibroblasts. PLoS One. 2014; 9(9):e107890.

45. Bouchareychas L, Grössinger EM, Kang M, Qiu H, Adamopoulos IE. Critical Role of LTB4/BLT1 in IL-23-Induced Synovial Inflammation and Osteoclastogenesis via NF- $\kappa$ B. J Immunol. 2017; 198(1): 452-460. 
46. Di Gennaro A, Haeggström JZ. Targeting leukotriene B4 in inflammation. Expert Opin Ther Targets. 2014; 18(1): 79-93.

47. Traianedes K, Dallas MR, Garrett IR, Mundy GR, Bonewald LF. 5 -Lipoxygenase metabolites inhibit bone formation in vitro. Endocrinology. 1998; 139(7): 3178-84.

48. Davidson EM, Rae SA, Smith MJ. Leukotriene B4, a mediator of inflammation present in synovial fluid in rheumatoid arthritis. Ann Rheum Dis. 1983; 42(6): 677-679.

49. Gheorghe KR, Korotkova M, Catrina AI, Backman L, af Klint E, Claesson HE, et al. Expression of 5-lipoxygenase and 15-lipoxygenase in rheumatoid arthritis synovium and effects of intraarticular glucocorticoids. Arthritis Res Ther. 2009; 11(3):R83.

50. Chen H, Dzitoyeva S, Manev H. 5-lipoxygenase in mouse cerebellar purkinje cells. Neuroscience. 2010; 171(2): 383-389.

51. Ahmadzadeh N, Shingu M, Nobunaga M, Tawara T. Relationship between leukotriene B4 and immunological parameters in rheumatoid synovial fluids. Inflammation. 1991; 15: 497-503.

52. Goetzl EJ, Pickett WC. The human PMN leukocyte chemotactic activity of complex hydroxy-eicosatetraenoic acids (HETEs). J Immunol, 1980, 125(4) 1789-1791.

53. Chabane N, Zayed N, Benderdour M, Martel-Pelletier J, Pelletier JP, Duval N. Human articular chondrocytes express 15-lipoxygenase-1 and -2: potential role in osteoarthritis. Arthritis Res Ther. 2009; 11(2):R44.

54. Hulten LM, Olson FJ, Aberg H, Carlsson J, Karlstrom L, Boren J, et al. 15-Lipoxygenase-2 is expressed in macrophages in human carotid plaques and regulated by hypoxia-inducible factor-1alpha. Eur J Clin Investig. 2010; 40: 11-17.

55. Magnusson LU, Lundqvist A, Karlsson MN, Skalen K, Levin M, Wiklund $\mathrm{O}$, et al. Arachidonate 15-lipoxygenase type B knockdown leads to reduced lipid accumulation and inflammation in atherosclerosis. PLoS One. 2012; 7(8):e43142.
56.Xu XC, Shappell SB, Liang Z, Song S, Menter D, Subbarayan V, et al. Reduced 15S-lipoxygenase-2 expression in esophageal cancer specimens and cells and upregulation in vitro by the cyclooxygenase- 2 inhibitor, NS398. Neoplasia. 2003; 5: 121-127.

57. Jiang WG, Watkins G, Douglas-Jones A, Mansel RE. Reduction of isoforms of 15-lipoxygenase (15-LOX)-1 and 15-LOX-2 in human breast cancer. Prostaglandins Leukot Essent Fatty Acids. 2006; 74: 235-245.

58. Wang D, Chen S, Feng Y, Yang Q, Campbell BH, Tang X, et al. Reduced expression of 15-lipoxygenase 2 in human head and neck carcinomas. Tumour Biol. 2006; 27: 261-273.

59. Kobe MJ, Neau DB, Mitchell CE, Bartlett SG, Newcomer ME. The structure of human 15-lipoxygenase-2 with a substrate mimic. J Biol Chem. 2014; 289(12): 8562-8569.

60. Bazan NG, Musto AE, Knott EJ. Endogenous signaling by omega-3 docosahexaenoic acid-derived mediators sustains homeostatic synaptic and circuitry integrity. Mol Neurobiol. 2011; 44: 216-222.

61. Feltenmark S, Gautam N, Brunnstrom A, Griffiths W, Backman L, Edenius C, et al. Eoxins are proinflammatory arachidonic acid metabolites produced via the 15-lipoxygenase-1 pathway in human eosinophils and mast cells. Proc Natl Acad Sci USA. 2008; 105: 680-685.

62. Liagre B, Vergne P, Rigaud M, Beneytout JL. Arachidonate 15-lipoxygenase of reticulocyte-type in human rheumatoid arthritis type B synoviocytes and modulation of its activity by proinflammatory cytokines. J Rheumatol. 1999; 26(5): 1044-1051.

63. Chen K, Yan Y, Li C, Yuan J, Wang F, Huang P, et al. Increased 15-lipoxygenase-1 expression in chondrocytes contributes to the pathogenesis of osteoarthritis. Cell Death Dis. 2017; 8(10):e3109.

64. Yacoubian S, Serhan CN. New endogenous anti-inflammatory and proresolving lipid mediators: implications for rheumatic diseases. Nat Clin Pract Rheumatol. 2007, 3: 570-579. 